\title{
La resolución de la identidad en las hijas de la posmemoria: Narrativas fílmicas del siglo XXI
}

\section{Nohora Viviana Cardona/Cleveland State University}

\section{Resumen}

El presente trabajo analiza de manera paralela los documentales Los rubios de Albertina Carri (2003), Papá Iván de María Inés Roqué (2004) y Pizarro de Simón Hernández (2016), protagonizados por hijas de miembros de grupos guerrilleros tanto de Colombia como de Argentina. Carri, Roqué y María José Pizarro, quien aporta la voz y la mirada sobre la que se articula el filme de Hernández, indagan en sus procesos identitarios tratando de entender los conflictos entre paternidad y militancia política que vivieron sus progenitores. El marco crítico incluye la noción de posmemoria que propone Marianne Hirsch y el cuestionamiento de la misma que propone Beatriz Sarlo.

Palabras clave: posmemoria, militancia política, el Hombre Nuevo, resolución identitaria, guerrillas, mujeres en el cine

\begin{abstract}
This study analyzes the documentary films Los rubios by Albertina Carri (2003), Papá Iván by María Inés Roqué (2004), and Pizarro by Simón Hernández (2016), in which the main characters are daughters of guerrilla leaders in Colombia and Argentina. Carri, Roqué, and María José Pizarro, who provides the voice and gaze that articulates Hernández's film, research their identity quests, trying to understand the conflicts between fatherhood and their progenitors' political militancy. The critical framework includes Marianne Hirsch's notion of postmemory and Beatriz Sarlo's questioning of this concept.
\end{abstract}

Keywords: postmemory, political militancy, the New Man, identity resolution, guerrilla groups, women in film.
Rastrear, socavar, desenterrar, marcan la voluntad de hacer aparecer los trozos de cuerpo y de verdad que faltan para juntar así una prueba que complete finalmente lo incompletado por la justicia.

Nelly Richard, Fracturas de la memoria ${ }^{1}$

María José Pizarro, Albertina Carri y María Inés Roqué, colombiana, la primera y argentinas, las dos últimas, protagonizan, cada una a su modo, los documentales Pizarro (2016), Los rubios (2003) y Papá Iván (2004) respectivamente, que dan cuenta no sólo de dos convulsos momentos en la historia de estas naciones latinoamericanas, sino de sus búsquedas identitarias, erigidas desde el punto nodal de la militancia política de sus progenitores. María José Pizarro es la hija de Carlos Pizarro Leongómez, el asesinado dirigente del movimiento M-19 y de Myriam Rodríguez, también miembro del M-19; Albertina Carri es la tercera de las hijas de Roberto Carri y Ana María Caruso. Carri fue un reconocido sociólogo y profesor, que ejerció su cátedra en la Universidad de Buenos Aires y que integró las filas de Montoneros. Caruso, por su parte, fue profesora de literatura y latín y también era miembro de Montoneros. Por último, María Inés Roqué es la hija de Azucena Rodríguez y Juan Julio Roqué, líder del movimiento Montoneros y también desaparecido, durante la época de la dictadura en Argentina, al igual que la pareja Carri-Caruso. ${ }^{2}$

Aunque estamos hablando de países y épocas diferentes, lo cierto es que las hijas de estos dirigentes de la izquierda latinoamericana, que dejaron de lado sus respectivos proyectos académicos para pasar a una militancia guerrillera, tienen mucho en común en relación con la manera en la que han tratado de acercarse al entendimiento de la prematura desaparición de sus progenitores y el modo de entender este traumático evento en sus vidas.

Esta investigación muestra dichos acercamientos, pero también las similitudes y las diferencias en la visión de Pizarro, Carri y Roqué sobre la militancia de sus progenitores y el modo en la que esta afectó sus jóvenes existencias. Con este objetivo, se indaga en un corpus compuesto por los tres filmes ya nombrados y por la correspondencia que tanto Carlos Pizarro como los padres de Carri dejaron. Las cartas del primero fueron publicadas en el libro De su puño y letra (2015) y las de Carri y Caruso fueron dadas a conocer como apéndice del guión de Los rubios, publicado por Albertina Carri (2007). 
Para realizar una aproximación a los tres documentales que focalizan las experiencias de María José Pizarro, Albertina Carri y María Inés Roqué vamos a partir del concepto de posmemoria, término propuesto por la crítica estadounidense Marianne Hirsch en su texto Family Frames. Photography, Narrative, and Postmemory. Hirsch afirma que "Postmemory characterizes the experience of those who grow up dominated by narratives that preceded their birth, whose own belated stories are evacuated by the stories of the previous generation shaped by traumatic events that can be neither understood nor recreated" $(1997,22)$. Por esta razón, no son extrañas las palabras o expresiones como piezas de puzzle, pasado fragmentado, recuerdos nebulosos o cortinas de humo que Pizarro, Carri y Roqué emplean para referirse a su difícil trasiego en la búsqueda de respuestas sobre el quehacer político de sus padres y su desaparición/muerte a causa de éste. Es preciso anotar que, aunque nos referiremos a la militancia tanto de los padres como de las madres, haremos más énfasis en los reclamos de las hijas a las figuras paternas partiendo de la apreciación de Ana Amado (2009), quien afirma que aunque resulta problemático atribuir cortes de género a la producción documental argentina que trabaja esta temática sí es un hecho "que las hijas mujeres fueron pioneras en ubicar en el centro de la representación a la figura paterna y a su generación para desestabilizar a ambas" (170).

Simón Hernández, director de Pizarro, que recoge la investigación de la misma María José Pizarro, como ya hemos anotado, realiza el filme con recursos del Fondo para el Desarrollo Cinematográfico de Colombia (2012), del Mercado de Coproducción de Señal Colombia (2013) y del Tribeca Latin America Fund (2014). Se trata de un documental para televisión que gana el Premio India Catalina de 2016 y que tuvo un proceso de elaboración de siete años. Las primeras imágenes de Pizarro muestran a María José en el centro de un set en el que voz y claqueta le piden que inicie una historia sobre las cargas familiares -como lo dice la presentación del trabajo documental en su página oficial-, esas que le siguen pesando dos décadas después del asesinato de su padre, el día 26 de abril de 1990. Las tomas de Pizarro Leongómez en uniforme camuflado alternan con la voz de su hija mayor, que le reclama su ausencia y el hecho de no haber cuidado de su vida, lo que la habría librado de la soledad, las depresiones y esa nada que la posee en los exilios que inicia desde que era una niña. "A mí me dejan porque hay algo más fuerte que no permite que estemos juntos" declara María José con voz tranquila. Se refiere a la militancia de su padre y también a la de su madre, Myriam Rodríguez, quien se levanta en armas como su padre. Por esta razón, es evocada por algunos testigos de sus acciones en aquella época como la mujer que guardaba una granada entre los pañales de su hija para protegerse de la persecución del gobierno después del robo de armas que el M-19 realizó en el Cantón Norte del Ejército en Bogotá. ${ }^{3}$ Pizarro hija comenta en el texto De su puño y letra lo que ocurrió con los miembros y seguidores de los grupo guerrilleros: "En ese tiempo, los integrantes y simpatizantes de los movimientos insurgentes fueron duramente perseguidos, se llevaron a cabo detenciones y allanamientos arbitrarios, torturas, desapariciones forzadas y otras violaciones a los Derechos Humanos" (Pizarro 2015, 44). ${ }^{4}$ Rodríguez se nos revela entonces lista para defenderse de dicha persecución en una imagen poderosa compuesta por la díada madre-militante que alterna los cuidados higiénicos de su bebé con un arma reservada para protegerse de cualquier ataque. Este comportamiento resulta muy similar al de Ana María Caruso, la madre de Albertina Carri, quien es descrita en el documental por una de sus compañeras de militancia como una suerte de "Susanita pero con alma de Rasputín". Sin embargo, en el juego de coincidencias y disimilitudes, el reclamo que también hace Carri a sus padres es menos calmado que el de Pizarro. Podemos afirmar esto si analizamos aquellos tramos en los que la argentina decide presentar lo que siente desde una emocionalidad sin represiones, en contraste con la hija de Pizarro, quien parece haber tamizado sus sentimientos mediante los largos años de investigación sobre la militancia de sus padres, la reflexión intelectual que hace de ésta y la necesidad imperiosa que siente de participar como agente activa del proceso de paz colombiano.

En relación con lo planteado anteriormente, Carri realiza su queja cuestionando a sus padres por su lucha política, que deriva en el abandono de ella y de sus dos hermanas Andrea y Paula. Lo hace por medio de los interrogantes que lanza en el filme, pero también lo grita, de modo dolorido, ante la cámara a través de la representación que hace de ella la actriz Analía Couceyro. De hecho, la situación resulta tan traumática para Carri que decide incorporar al filme a Couceyro, para que la doble en aquellas escenas cuya carga emocional le resulta imposible de soportar. De paso, propina varios bofetones metafóricos a la militancia de sus padres, ignorando, de modo premeditado, los testimonios de sus amigos en lo referente al trasegar político de estos. En razón de ello, se muestra conmovida solo en aquellos momentos donde los compañeros de militancia de sus progenitores se refieren a algún aspecto humano de Roberto Carri y Ana María Caruso. De manera obvia, queda claro que la pregunta identitaria de Carri pasa por el reproche a la militancia política de sus padres, a la que culpa de su orfandad temprana. ${ }^{6}$

En el caso de Papá Iván, de Roqué, es interesante notar cómo el fallecido dirigente montonero es presentado como un hombre tan convencido de su proyecto vital como ideólogo y líder del grupo guerrillero que, incluso en las cartas que envía a sus hijos, opta por privilegiar su nombre de combate, esto es, Iván, sobre su verdadero nombre, Juan Julio. ${ }^{7}$ El sustrato que emplea la documentalista para encontrar respuestas a sus preguntas identitarias es la 
indagación sobre la elección de este nombre, así como la capa de sentido que este envuelve en cuanto a su militancia y la ruptura de una domesticidad que, a ojos de Juan Julio Roqué, impedía su labor de liderazgo. De entrada, en Papá Iván, nos encontramos con las mismas herramientas que emplean tanto Pizarro como Carri para tratar de recomponer un pasado que se muestra elusivo: fotos, cartas, visitas a archivos y testimonios dentro del ámbito familiar y fuera de él. María Inés Roqué tiene una postura muy clara frente a su opinión sobre el conflicto paternidad-militancia al manifestar, en el filme, su desconfianza hacia la narrativa heroica guevariana, tan en boga en aquel tiempo, afirmando: "Yo, una vez, dije que preferiría tener un padre vivo que un héroe muerto". Por esta razón y, seguramente, para reforzar su rechazo a esa heroicidad impregnada de mesianismo, la cámara pasa de las fotos idílicas con el padre y sus hijos a la itinerancia de un vehículo desde el cual la voz en off de la directora expresa su queja por la imposibilidad de conocer lo acontecido con su padre, su militancia y su desaparición. El movimiento de travelling de la cámara por el paisaje, que parece rural, se enfoca en planos detalle descentrados de unas fotos de hombres para, después, en un plano de contrapicado, subir por la figura de un Cristo que está en una de las tumbas del gran conjunto de estas que muestra la escena. La muerte del padre y la imposibilidad de rendirle homenaje, en tanto que no existen restos humanos de este, están representadas por los rostros descentrados y la rapidez con la que la cámara impide precisar los nombres en las lápidas. A través del documental, sus sentimientos fluctúan entre la admiración que ha internalizado desde niña por el activismo de su padre y su disgusto por el abandono familiar al que la sometió a ella y a su hermano Iván Rafael. De alguna manera, reconoce que desea reconstruir, a través del filme, la faceta humana de su padre, pero también la política.

María José Pizarro, en abierto contraste con Carri, y de manera similar a Roqué, afirma sentirse parte de las luchas de su padre porque en ellas "dejó parte de su infancia", sin dejar de preguntarse la razón por la cual este, después de pasar por un proceso de amnistía, retorna a las armas y, por ende, a la clandestinidad. Por el tono que emplea la hija, parece compartir el parecer de su abuela Margoth -que se hace cargo de ella por un tiempo- quien le indica al líder del M-19 que volver a la guerra, después de haber concertado con el gobierno colombiano es un error. De hecho, le envía una carta a su hijo donde le expresa: "Yo estaba convencida de que íbamos hacia la paz. ¡Con el dolor y la sangre de las madres no se juega!" (Lara 2001, 286). Sobre este punto específico, al analizar lo que ambas expresan, sin duda, resulta más directo el cuestionamiento de Margoth Leongómez que el de su nieta María José.

También resulta diferente la manera en que estas hijas construyen, deconstruyen y reconstruyen las figuras de sus progenitores. En el caso del documental Pizarro, la hija acude a tomas de archivo de su padre como miembro del M-19 sin edulcorar que, en el seno de este grupo, se pasa de una lucha cargada de símbolos como el robo de la espada de Simón Bolívar y ciertas actividades que evocan al mítico Robin Hood, como apoderarse de camiones cargados de leche para repartir su contenido en barrios marginales, a una compleja guerra donde su padre es un importante cuadro guerrillero que planea y participa de actos que derivan en sucesos sangrientos, como la toma del Palacio de Justicia y, todo ello, en nombre de una militancia política. ${ }^{8}$ Quizá por el hecho anterior, María José Pizarro, en connivencia con el director Hernández, intenta equilibrar la mención de estos actos con entrevistas en las que Carlos Pizarro habla de lo ineludible que fue para él y para muchos de sus pares generacionales alzarse en armas para lograr una nación equitativa, fuerte, pacífica y preparada para los retos del siglo XXI. En una de las entrevistas que se le hacen, recogida en el documental, este declara que sus compatriotas se matan por una tradición de guerras civiles infinitas, lo que debilita a la nación colombiana y la hace menos fuerte y menos preparada para encarar la aspiración a una vida digna de quienes la conforman. ${ }^{9}$ Sin embargo, Carlos Pizarro insiste en dicho diálogo y, de manera enfática, en que hay que empezar a construir interlocutores para la paz. Piensa que, de este modo, se puede evitar el atrincheramiento en posiciones particulares que desconozcan al otro que piensa diferente. De manera obvia, y de cara a su participación en el proceso de paz que se vive en la actualidad colombiana -hay varias tomas de ella participando en marchas-, la hija del asesinado dirigente emplea la película a modo de hilo de Ariadna para permitirse descifrar sus laberintos identitarios o el puzzle -para mencionar la metáfora que ella usa- que le resulta la vida de ese padre fragmentado: "No sé quién era mi papá. Lo mío son momentos fugaces, recuerdos, flashes". También lo expresa, de manera similar, en el prólogo que escribe para el epistolario de su padre: "No puedo recordarlo riendo junto a mí, no puedo recordar su rostro, ni la forma como dicen dibujaba el aire con sus manos; no recuerdo su voz llena de esa fuerza capaz de movilizar a los hombres en busca de sueños" (Pizarro 2015, 18). No obstante, a medida que avanza el metraje del documental, resulta obvio que, la hija confundida en torno a la figura de su progenitor, toma partido. A causa de ello, ese padre, que María José manifiesta no conocer mucho, empieza a ser presentado en el filme y, en la voz de ella, como una suerte de romántico que decide "apostarle todo a la paz y que pierde por ello", como reza uno de los encabezados del periódico El Tiempo, diario que es empleado como fondo por el director mientras se registran tomas de la hija del dirigente del M-19 buscando información sobre este en archivos diversos. Los titulares y las imágenes que acompañan el discurso narrativo de la película, en las escenas siguientes, refuerzan la intención ya mencionada con encabezados como "Viraje a fondo, clamor nacional" o "Del fuego a la paz", en clara alusión al discurso de Pizarro sobre la necesidad de encontrar una salida negociada al conflicto armado en Colombia.

En esta parte del filme, se hace obvio que la hija sigue cuestionando al padre en su responsabilidad para con su 
familia, mas no al Pizarro militante, a quien defiende, de modo contundente, incluso cuando se refiere a la toma del Palacio de Justicia, pues afirma que los líderes del movimiento "estaban cuestionando desde adentro, pero no estaban buscando un acto terrorista". María José Pizarro marca su posición de manera enfática: "Yo no lo puedo ver como un terrorista desalmado. Sería el farsante más grande". Merced a este tipo de reflexiones, la niebla en la cabeza de la hija, que le impide recordar con propiedad a su padre, parece irse despejando. Como consecuencia de ello, el tratamiento que la película le da a Pizarro, a medida que transcurre, permite apreciar una focalización en la figura de este como cabeza de paz y no como coraza de guerra. Con estas metáforas hacemos uso de los tropos con los que el novelista Carlos Fuentes juega a la ambivalencia al examinar la figura histórica del dirigente del M-19 en su novela Aquiles o el guerrillero y el asesino, publicada de manera póstuma en 2016. ${ }^{10}$

De otro lado, en Los rubios de Carri la figura inaprehensible del padre que obstaculiza, problematiza o impide la resolución identitaria de la hija emerge desde un pasado que se oculta, se cuenta dosificado, se moldea desde un interés particular o se silencia por una cicatriz traumática. Si consideramos este filme y otros que tratan el mismo tópico advertimos, de modo evidente, la escisión que plantea Beatriz Sarlo en su libro Tiempo pasado. Cultura de la memoria y giro subjetivo. Una discusión, cuando analiza un corpus de objetos culturales en los que ve una intención posmemorística. Con respecto a la actitud que tienen los hijos de aquellos que fueron militantes en contra de la dictadura argentina, Sarlo observa dos posturas antinómicas. De un lado, están los hijos que prefieren mantenerse al margen del interés político de sus padres:

La sensación de una demasía política, que es claramente un signo de estos tiempos, podría llevar a suponer que Los rubios -a esta altura, vale insistir: la película que una hija de dos militantes políticos desaparecidos hace a partir de lo que ha pasado con sus padres- prefiere postergar la dimensión más específicamente política de la historia para recuperar y privilegiar una dimensión más ligada con lo humano, con lo cotidiano, con lo más personal de la historia de Roberto Carri y Ana María Caruso. (2006, 146-147)

Del otro lado, cuando Sarlo analiza los testimonios de algunos de los hijos de los desaparecidos, observa "una búsqueda de la verdad que no excluye la figura de los padres y su compromiso político" $(2006,153)$. Para Carri, el padre ausente es una víctima de la dictadura, pero, al tiempo, es el victimario de sus hijas. Un hombre tan convencido de la importancia de su rol político, que no dudó en sacrificar su papel como padre para darle todo el protagonismo a su accionar en la esfera pública. La cineasta Carri extiende esta cuenta de cobro a su progenitor y aunque no expresa su malestar de manera muy evidente, no duda en hacer distinción con la actitud de la madre tanto en la producción fílmica como en la publicación del guión de su película. Como ya hemos anotado en páginas previas, en el filme se puede notar la poca atención que Carri presta a los amigos de sus padres cuando hablan de lo político. Debido a esta razón, la observamos, a menudo, dándole la espalda a los testimonios grabados de ellos, que reproduce en una videocasetera, al tiempo que mira su computador o escribe sus propias ideas sobre la manera en la que concibe la política. Incluso, como una suerte de desprecio a la producción escrita de su padre en la que se puede apreciar su ideario, dedica los apartes que se leen en el documental "extraídos de su libro" no a las reflexiones de Roberto Carri, el sociólogo, sino a los epígrafes que él emplea, es decir, discursos de una autoría diferente a la suya. De igual manera, en el guión de Los rubios, la directora privilegia cartas en las que se muestra el genuino interés de su madre -encarcelada junto al padrepor resolver la vida cotidiana de sus hijas, en contraste con las fórmulas de escritura epistolar del padre, en las que este se limita a escribir unas pocas expresiones de saludo y despedida. En dichas cartas, Ana María Caruso no sólo indaga y aconseja en múltiples aspectos de la vida de sus hijas relacionados con la dieta que llevan, la manera en que deben vestirse, con quién deben vivir en su ausencia, sino que también se ve excepcionalmente preocupada por la formación académica de sus tres hijas. La lectura de las cartas a las hijas permite observar el trabajo que se toma su madre al recordar las lecturas que ha hecho, en las diferentes edades de su joven vida, con la finalidad de sugerirles los autores que deberían leer y hasta las mejores ediciones que existen sobre las obras que ella considera importantes para la formación de Andrea, Paula y Albertina. El documental de Carri y las diferentes estrategias en las que esta expresa el rechazo por la labor política de sus progenitores son una muestra fehaciente de lo que expresa Sarlo cuando habla de los hijos que, en retaliación al decidido activismo político de sus padres, optan por tener una actitud diametralmente opuesta.

Pese a que Carri no considera posible deslindar la vida de su padre de la militancia política, y por eso el documental no puede ser ajeno a ésta, sí apuesta por adentrarse en una faceta más humana de su progenitor, tal y como lo expresa Laia Quílez (2007): "Tal vez sea con esa intención de convertir la "estatua" en "cuerpo" -o, dicho de otro modo, de recuperar el lado más humano y por ello el más contradictorio, del padre ausente- que la cineasta argentina decide incluir en su trabajo fílmico un tipo de testimonio que supere, por su heterogeneidad, el del sobreviviente militante" (78). Este padre ausente, incluso en las cartas a Albertina y a sus hermanas, dado que se limita a poner una o dos líneas al final de las extensas cartas de Ana María Caruso, se diferencia, en gran medida, del padre cariñoso en las epístolas que es Carlos Pizarro Leongómez. ${ }^{11}$ Curiosamente, este se parece en ello no al padre, sino a la madre de Carri. Como se puede apreciar en el filme Pizarro, la escritura del asesinado 
dirigente del M-19 es cálida, de gran factura poética y, en ella, alterna las palabras de amor a su hija con los consejos que le quiere dar para su vida futura y su esperanza en un mejor porvenir para Colombia: "Mi niñita tengo en mi alma un montón de risas y mariposas. Algún día juntaremos los soles que tú pintas con los que yo hago nacer. La gente nos mirará y querrá tener nuestras sonrisas". También se advierte en estas misivas la confesión de la culpa por haber antepuesto su lucha política a su rol de padre: "Tengo atragantadas un sinfín de caricias que sólo tú, mi hija, podías despertar y deberías recibir. Las guardo en mí".

De su puño y letra, el epistolario al que ya nos hemos referido anteriormente, posibilita que María José Pizarro recopile, edite y publique numerosas cartas de su padre. Emplea, como material principal, las epístolas de su progenitor que le entregan Margoth Leongómez y Myriam Rodríguez cuando ambas deciden que ella tiene la edad suficiente para entenderlas. Resulta obvio que las cartas se imbrican en el filme y que ambos materiales permiten el recorrido posmemorístico de la hija. Tal y como lo afirma Hirsch, los acontecimientos que afectan a la descendencia ocurren antes del nacimiento de los hijos (Hirsch 1997, 22). En el caso concreto que nos interesa, la narrativa de la militancia política del padre queda evidenciada en las cartas mucho antes del nacimiento de María José. De hecho, aquellas con las que se abre el libro datan de 1974, cuando Pizarro ya había desertado de la FARC ${ }^{12}$ y se refugiaba donde una pareja de amigos ${ }^{13}$ para pensar en su siguiente paso como militante de las causas de la izquierda política. La mayoría de los escritos están dirigidos a Myriam Rodríguez, pero también encontramos textos dirigidos a su madre, a su padre, a sus hermanos, a su hija María José, a su hija de crianza, Claudia, a algunos de sus amigos, al Papa Juan Pablo II y a Álvaro Gómez Hurtado. Pizarro hija también presenta, como una suerte de rescate del ideario político de su progenitor, las últimas intervenciones que tuvo éste en la X Conferencia del M-19 en el año de 1989 en Santo Domingo, Cauca; ${ }^{14}$ las palabras que pronunció el 8 de marzo de 1990 cuando entregó su arma envuelta en la bandera de Colombia como símbolo del fin de su vida como guerrillero; sus palabras en el lanzamiento de su candidatura a la presidencia el 19 de abril de 1990 en Bogotá; una alocución a los colombianos el 20 de abril de 1990 como candidato a la presidencia y su último discurso en público el 22 de abril de 1990, en la plaza Alfonso López de Valledupar. De toda esta correspondencia y recopilación de discursos, podemos observar dos facetas de Pizarro, que María José visibiliza con la publicación de estos materiales diversos: su gran preocupación en torno a sus deberes como padre de una familia con la que solo ha podido compartir momentos fugaces y otra que ya hemos anotado como punto central del documental Pizarro, esto es, la preocupación del dirigente del M-19 por el proceso de paz en Colombia. Ambas facetas lo hacen un padre distinto a los de Carri y Roqué y, en este sentido, las diferencias generacionales cuentan, pues Pizarro no solo es once años más joven que Carri y Roqué, sino que su vida, a diferencia de lo que ocurre con ellos, desaparecidos en el año de 1977, llega hasta la década de los noventa. En aquel momento, consideraba que, como dirigente de la izquierda, debía de ser capaz de cuestionar las ideologías que lo habían guiado a medida que avanzaba el tiempo, en aras de conseguir lo que para él resultaba prioritario en Colombia. Este apartado de un discurso suyo así lo prueba:

Hemos cometido la herejía de aportarle a la posibilidad de construir una sociedad reconciliada, cuando todos los días se intenta fomentar el odio y la violencia. Nos hemos colocado por encima de esos viejos dogmas que nos condenaban a vivir anclados en el sesenta y le hemos dicho a la guerrilla, a las fuerzas armadas, a los partidos y al Estado que tenemos que empezar a modernizarnos y que estamos en el noventa y al borde del siglo XXI, que los dogmas del sesenta están agotados y que deben ser definitivamente superados. (Pizarro 2015, 296)

Con claridad manifiesta, Pizarro asume que las ideologías deben ser revisadas en consonancia con los tiempos para que no se conviertan en dogmatismos ciegos que estanquen la necesaria evolución de la humanidad y sus derroteros.

En cuanto al hombre de la esfera más privada, podemos realizar varias anotaciones. Su preocupación por integrar una familia, en la que tanto el padre como la madre asuman las funciones de dotar a los hijos de un entorno de afecto y de enseñanza de los valores, en los que cree desde una edad temprana, ya aparecen en la primera carta que abre De su puño y letra. Lo podemos advertir cuando se dirige a Rodríguez expresándole: "Quiero ofrecerte un presente con grandes aspiraciones, lograr hacerlas tuyas, combatir juntos, quiero en fin soñar también con un hijo nuestro, que haga con Claudia una bella pareja" (Pizarro 2015, 23). No obstante, desde el inicio de su relación con ella, es consciente de que no puede ofrecer un vínculo tradicional en la medida en que se siente entregado al compromiso de la causa política en la que cree: "Es también una locura pedirte que me sigas, ¿qué tengo para darte? Sólo puedo ofrecerte fantasías, pero la vida dará patadas duras contra ellas, hablo de un hogar del que el destino posiblemente me arrancará" (Pizarro 2015, 26). El joven de veintitrés años se confiesa enamorado, pero no promete nada ni a corto ni a largo plazo y termina por expresar que, si Rodríguez se decide a seguirlo, quizá "tu locura sería mayor que la mía" (Pizarro 2015, 26). A través de todo el epistolario, que va desde septiembre de 1974 hasta septiembre de 1982 -si consideramos sólo las cartas que dirige a su familia- Pizarro habla tanto de la política como de su paternidad y su pensamiento fluctúa en torno a lo que resulta prioritario para él en el momento en que escribe sus cartas. Se declara ilusionado después del nacimiento de su hija María José, autodefiniéndose como un artesano de la familia y también como un paterfamilias de una estirpe destinada a ser feliz. No obstante, simultáneamente, considera que él ya ha entrado a la historia y que, por esta 
razón concreta, tiene la responsabilidad de dejar el hogar que ha creado junto a Myriam y sus hijas. Es justamente la época en que empieza a firmar las cartas de amor para ella primero "como patriota" y, después, como "hombre". En ese sentido, es necesario acudir a la mítica figura de Ernesto Guevara (1977) para poder explicarse los razonamientos de Pizarro y los entresijos de su reflexionar en torno a este aspecto. Guevara expone en el texto El socialismo y el hombre nuevo, su pensamiento político en relación con el denominado Hombre Nuevo, las bases materiales del socialismo y el debate sobre la gestión económica en Cuba. Guevara no es muy estricto mencionando las características de este tipo de modelo, pero estas se pueden inferir de lo que dice su carta. Cabe anotar que, aunque acuña el rótulo de Hombre Nuevo para manifestar sus características, acude a diferentes denominaciones. Así, lo llama primeramente "vanguardia"; después, "el hombre del futuro"; luego, "dirigente" y, finalmente, "revolucionario de vanguardia", es decir, toda una vuelta retórica en su carta que termina por adoptar, al final, el término inicial. Según este texto, el Hombre Nuevo guevariano debe formarse académicamente, ejercitar su físico, conocer la tecnología de vanguardia, ser laborioso, austero, sacrificado y liberarse de la concepción de considerar su trabajo sólo como un medio de subsistencia. Además, debe estar atravesado por una gran dosis de amor a la humanidad. Este amor del que habla Guevara exige al Hombre Nuevo que renuncie incluso a su rol familiar como padre o madre para concederle toda la importancia a la tarea de llevar a cabo la revolución. "Los dirigentes de la revolución tienen hijos que en sus primeros balbuceos no aprenden a nombrar al padre; mujeres que deben ser parte del sacrificio general de su vida para llevar a cabo la revolución a su destino" (Guevara 1977, 15). Esta última es un proceso que tiene como fin la construcción del proyecto socialista a escala mundial. En cuanto a la preocupación por el bienestar material de los hijos, Guevara piensa que el hombre paradigmático debe aspirar a que sus hijos tengan lo que todos tienen y carezcan también de lo que el grupo carece. Para el Hombre Nuevo no debe ser importante la calidad de la carne que se come, la belleza de los sitios que se visita ni los objetos que pueda comprar con su salario. Todas están preocupaciones materiales deben de estar ausentes del proyecto para el que se quiere modelar este Hombre Nuevo. Resulta obvio que Pizarro, como todos los jóvenes latinoamericanos adscritos a proyectos políticos de izquierda en ese tiempo, tiene en mente los dictados de Guevara cuando prioriza su patriotismo antes que su papel de esposo y padre en la esfera privada. Pese a ello, su anhelo de "paternar" es tan fuerte que no sólo se siente comprometido con su hija biológica María José sino que se considera un padre para Claudia, ${ }^{15}$ la hija mayor de Myriam Rodríguez y como tal se comporta. También, de modo muy consciente, se siente un poco como el reemplazo de su padre Juan Antonio Pizarro en relación a su hermana Nina. Esto se hace evidente cuando ambos son encarcelados por su actividad subversiva y él se constituye en el mayor apoyo de su hermana para que ella pueda sobrellevar su cautiverio. Nada en estas relaciones que establece resulta sencillo para él. Aunque dice trabajar para ser consecuente con el lugar que ya tiene en la historia y asegura entender la clase de sacrificios que ello exige de él, las culpas sobre lo que él mismo califica de irresponsabilidad con su pequeña familia lo abruman: "Tengo plena confianza en ti, en tu coraje, veo los múltiples problemas de toda índole que tendrás que afrontar, y lamento estar lejos, me siento estéril, también algo irresponsable, pero no hay por el momento alternativas" (Pizarro 2015, 51). En este mismo orden de ideas, se muestra atento a la educación no solo de sus hijas sino también a la de su sobrina Alejandra, hija de su hermana Nina. En razón de ello, le manifiesta a su madre que no desea que los niños de la familia Pizarro se eduquen en los Estados Unidos, lugar donde ella se ha establecido. ${ }^{16}$ Se deduce que, al consignar este tipo de pensamientos en su carta, el paterfamilias y el militante se unen simbióticamente para dejar sentada, sin equívocos, su postura al respecto:

Pero los Estados Unidos tienen algo bello, es un país que ama a los niños... Lo que sí no desearíamos es que nuestros hijos fueran educados en los EE.UU. a partir de cierta edad queremos que nuestros hijos sean colombianos con todo lo bueno y lo malo que ello significa. Y para ser colombianos tienen que amar a un país que lucha contra la pobreza y no a un país que conoce el devenir de la abundancia. (Pizarro 2015, 81)

Sin embargo, como ya se ha expresado, el conflicto entre lo que considera deber revolucionario, sus sentimientos de soledad y sus anhelos por cumplir, a cabalidad, con su papel en el seno de su familia le hacen rebelarse, al menos sobre el papel, con su decisión de priorizar su compromiso político: "Estás lejos y tu ausencia es soledad aún en medio de la multitud. Es fácil requerirte y duro no tenerte, así políticamente me explique mil cosas que todo lo expliquen y justifiquen. Como debe ser, a veces la política es una joda" (Pizarro 2015, 84). El aislamiento, debido a los largos años de encarcelamiento en La Picota y la angustia que le causa que sus hijas estén privadas de su padre y de su madre debido a que Myriam también está confinada en la cárcel de mujeres de Bucaramanga, resultan en la ecuación política igual a "joda", esto es, molestia, carga o lastre. Para el combatiente Pizarro, pensar de este modo resulta conflictivo cuando considera los preceptos que guían esa suerte de subjetividad colectiva que representa El Hombre Nuevo. Podemos deducir entonces que Pizarro no se resigna a la desconexión con su familia por el hecho de ser un cuadro importante en su organización. Incluso se atreve a confesar que, aunque suene a herejía, para él, es de suprema importancia saberse centro de cohesión y realización del hogar que ha formado con su compañera:

Que lo anterior suena herejía me importa poco, tú eres mi clan, tú eres mi hogar y aunque estemos en medio de una torrente ${ }^{17}$ multitudinaria de hombres y mujeres, siempre sabré reconocer lo que a nosotros 
corresponde, la individualidad que se forma y que se pierde en una relación de familia y en ella como un centro de cohesión y realización tú y yo. (Pizarro 2015, 105).

Aunque en el documental de Hernández se dan atisbos de ese padre al que se muestra como una persona cariñosa con sus descendientes y comprometida con la enseñanza de los valores en los que cree, es realmente, mediante la lectura de las cartas, donde llegamos a entender la complejidad y la naturaleza ambigua y cambiante de los sentimientos de un hombre que ha hecho una profesión de fe en relación con un proyecto comunitario revolucionario. No obstante, ese mismo hombre no se resigna a sufrir por los dogmatismos que le impiden cuidar de su familia biológica del mismo modo en que lo hace con la que él denomina su familia del M-19 o con sus proyectos políticos. De alguna manera, intenta conciliar estos afanes cuando reitera su amor a Myriam y su afecto a sus hijas sin olvidar amarrar estos dos afectos al imperativo político que lo guía: "Voy hacia tu bahía con afán de permanecer, con las viejas ganas de criar mis hijos y sembrar libertades" (Pizarro 2015, 179).

En el caso de los documentales argentinos, hay matices de lo que hemos planteado a partir del análisis del documental Pizarro y también del epistolario De su puño y letra. A diferencia de quienes recriminan a Albertina Carri por no darle un papel central en su documental al pensamiento político de sus padres o al de los contemporáneos de estos, pensamos que su apuesta por este modo de contar la historia en la pantalla no tiene la pretensión académica de contar la historia de su país de origen del mismo modo en que lo haría la historiografía tradicional. También resulta obvio que su desinterés por el discurso político de quienes acompañaron a sus padres en la lucha armada contra la dictadura hace parte de los cuestionamientos que expresa con respecto a su ideología y su manera de actuar. Como consecuencia, decide centrar la historia en ella y en las maneras en las que le afecta la ausencia de sus padres, con quienes mantiene una relación ambivalente que va desde un reproche cargado de rencor - por no haber privilegiado su deber como padreshasta la admiración por lo que ella percibe como una entrega consecuente con los ideales que tenían. En el apartado donde explica el proceso de preproducción de Los rubios Carri sostiene:

Al ver vivos a los amigos de mis padres, quienes también habían participado de la lucha, armada o no, y que se había exiliado, no pude más que sentir desasosiego: ellos no habían sido consecuentes con su lucha pero estaban vivos. En esos momentos mis padres se me figuraron como dos héroes, los únicos capaces de creer y de luchar sin sopesar intereses personales. Los imaginé como suicidas, como Cristos, como superhéroes intelectuales, como geniales, como importantes, como pusilánimes, como cobardes, como fracasados, pero nunca en ese tiempo pude pensarlos como humanos. (Carri 2007, 18)

Es justamente esa falta de humanidad de las figuras parentales la que Carri intenta descubrir con su acercamiento diferente. Por eso, "la despolitización" de la que se acusa a su filme, argumento que puede ser refutado de diversas maneras, es más la elección que hace la directora de un punto de vista -el de una joven directora que aplica la hermenéutica de la sospecha a los discursos políticos que han quedado consignados en los libros de su padre, a lo que sostienen los compañeros de militancia de este, a lo que cuentan los testigos del vecindario donde vivieron los Carri hasta el secuestro de Roberto y Ana María e incluso a los recuerdos de ella misma cuando era una niña y de los que duda de manera constante. Sus palabras no pueden ser más claras: "La razón por la cual no quiero encarar este trabajo desde ellos sino desde mí, reside fundamentalmente en que ya no sé qué son, ni que fueron. Persisten como un sentimiento que titila y va de la desesperación al odio y de la angustia máxima a la admiración" (Carri 2007, 18). De otro lado, si la culpa por estar al interior de una organización guerrillera clandestina y dejar, por ello, en un segundo plano a la familia aparece en Carlos Pizarro, no hay indicio de que esto haya ocurrido con Roberto Carri. En el guión de Los rubios, Carri incluye la transcripción de una serie de entrevistas que realiza a los amigos de sus padres y que, luego, decide no incluir en la película. De este modo, conocemos los testimonios de Ricardo Carri, Jorge Carpio y Lila Pastoriza. Todos ellos concuerdan en que Roberto Carri era un iluminado marxista, muy idealista, convencido de que el poder se podía tomar a través de las armas, pero también el más rígido en sus posturas: "Varios amigos estaban en Lealtad y había unas peleas terribles, sobre todo de parte de tu viejo, que era el más duro, el que tenía posiciones más rígidas" (Carri 2007, 71). También afirman que Ana María Caruso no era tan inflexible en sus posturas como su pareja, pero que su intención de no irse al exilio, como se lo sugirieron a ambos, se debió al compromiso que sentían ellos por culminar con éxito una empresa en la que ya se habían comprometido muchas personas. ${ }^{18}$

En el caso de Papá Iván, observamos a una María Inés Roqué que muestra también sentimientos ambiguos cuando se refiere a su padre. En el documental, confiesa sentirse orgullosa en su exilio mexicano cuando los compañeros de este le hablan de él y sus cualidades de liderazgo y entrega a la causa pero, al tiempo, emplea la figura de la madre, Azucena Rodríguez, también participante del movimiento guerrillero, para que sea ella quien revise discursivamente aquellos aspectos que no le convencían del accionar de Juan Julio Roqué en Montoneros. ${ }^{19}$ En el filme, Rodríguez desaprueba el empleo de armas y los actos de terrorismo en los que se implicó su esposo cuando estuvo a la cabeza de la organización de los Montoneros, como muestran sus palabras: 
Sé que la violencia existe en todas las formas, en las formas más sutiles. Sé que hay violencia en las diferencias que existen, pero yo no podría ejercer la violencia ni aún contra los que la han ejercido arbitrariamente. Porque además siempre sentí que era inmolar tu vida. Y pensé que la vida es para vivirla, no para inmolarla. Porque creo que tiene sentido la lucha que haces cada día con tus hijos, con lo que haces, con lo que piensas, con lo que construyes. $\mathrm{Y}$ es que eso era un proyecto que, que tenía como finalidad la muerte y frente a eso, me rebelo y me rebelé siempre.

Advertimos entonces que, de esta manera, Rodríguez desacraliza al Roqué militante. Aunque en cámara recuerda su gran formación académica, su especial sensibilidad con la gente menos favorecida y su entrega a la docencia, también se atreve a bajar del pedestal su figura, señalando las características poco encomiables que ella advierte en Roqué, como su decidida apuesta por la violencia. De hecho, afirma que él la llegó a considerar el único camino para conseguir las reivindicaciones sociales con las que soñaba. También se resiente de la manera abrupta en la que terminó su matrimonio, al darse cuenta de que ella no deseaba pasar a la clandestinidad como él. Esto último fue interpretado por ella como una muestra fehaciente de una gran inflexibilidad ideológica, muy en consonancia con los planteamientos de Ernesto Guevara cuando señala el modelo que debe seguir el Hombre Nuevo. No resulta por ello gratuito que la figura del Che Guevara aparezca de manera recurrente en la película, bien en foto, en grafiti o en el cuestionamiento que la hija hace al padre, al darle centralidad en el documental a la voz de su madre. Es Roqué entonces una descendiente que reivindica el legado de su padre, pero que también lo revisa y lo cuestiona.

Por último, en Pizarro, al cierre del documental, la escritura del padre se hace voz en su hija quien, de esta manera, sigue el imperativo paterno de mantener viva la memoria de quien le dio la vida: "No me olvides. No dejes que yo me muera en tu corazón". Pizarro hija no lo hace $\mathrm{y}$, además, pone de manifiesto que el rescate discursivo del padre trasciende la esfera íntima que les compete a ellos dos y se extiende al ideario político de aquel que, en su corazón y en el eje fílmico, termina por reconstruir como un héroe preocupado por las injusticias sociales y dispuesto a dar su vida en aras de acabar con ellas: "Rebélate contra toda injusticia que veas a tu lado. No importa si sufres un poco con ello". La demasía política que intenta contener Carri de diversas maneras en su documental no llega al filme de Hernández y tampoco, en éste, se acalla la voz de los compañeros del M-19, pero se escoge, de manera cuidadosa de qué se habla y por qué razones. Lo anterior se ilustra mediante el testimonio de Antonio Navarro Wolff, uno de los más reconocidos exmilitantes del M-19, a quien María José interpela en uno de los apartes de la película. Él le expresa que comprende su intención de buscar respuestas sobre lo acontecido en el pasado y, de manera empática, señala que quizá, si él hubiese muerto, sus hijos estarían haciendo lo mismo que ella. Sin embargo, le confiesa que, a pesar de saber quienes fueron los victimarios del atentado que casi le cuesta la vida, él, como víctima directa, ha decidido pasar la página de modo total $\mathrm{y}$ absoluto para ser consecuente con su ideario de excombatiente. Se hace evidente que el camino que le señala Navarro Wolff es el del perdón y el olvido concertados. Carri, en cambio, quiere saber quiénes desaparecieron a sus padres para que se haga justicia. Al saberla esquiva, desde sus años de infancia hasta el filme que le sirve de "exorcizador de demonios", recurre a mecanismos diversos como imaginar a sus padres abducidos por extraterrestres para no dirigir sus sentimientos de rencor a alguien en concreto o entrenar al hijo de su hermana para que declare, ante la cámara, que va a ajusticiar a los asesinos de sus abuelos: "Me gustaría filmar a mi sobrino de seis años, diciendo que cuando sepa quienes mataron a los papás de su mamá va ir a matarlos, pero mi hermana no me deja". ${ }^{20}$

Si consideramos las actitudes de los hijos de las víctimas directas, tanto de la dictadura argentina como del conflicto armado colombiano, advertimos que algunos de ellos rechazan la actitud militante de sus progenitores, pues consideran que la vida de estos estuvo atravesada por lo que en este trabajo se ha denominado "demasía política" y que los privó de ellos. El resultado en los descendientes, como Albertina Carri, suele estar atravesado por actitudes de indiferencia e incluso de absoluto rechazo con las ideas que defendieron sus ancestros. En contraste, para otros hijos como María Inés Roqué y María José Pizarro, se debe hurgar en el pasado para reconstruir la evanescente figura del progenitor -que se conoce más por el testimonio de los otros que por la experiencia propia- pero sin desligarla del militante político, como intenta hacerlo Carri. Si esta última se distancia de HIJOS (acrónimo para Hijos e Hijas por la Identidad y la Justicia contra el Olvido y el Silencio), quienes le reclaman haber postergado la dimensión más específicamente política de la historia, María Inés Roqué es capaz de sentir admiración por los actos de su padre. Ella los considera legados políticos de valor sin negarse a la posibilidad de cuestionar las aristas que menos le gustan de él, como son su creencia de que la vía más expedita para llegar al poder era la violencia, el abandono de su madre en razón de su negativa a seguirlo en la clandestinidad y su rol como padre. En ese mismo orden de ideas, María José Pizarro, como Roqué, también admira y cuestiona a su padre, pero inclina la balanza por lo primero. Cabe anotar que, en contraste con Carri y Roqué, Pizarro alcanza a recordar a un padre que depuso las armas, que volvió a la legalidad y que, al hacerlo, se convirtió en un fenómeno de masas cuando lanzó su candidatura a la presidencia, en la que enarboló un discurso encaminado a la consecución de la paz. Quizá, por ello, lo llega a definir en una entrevista publicada en el diario El Tiempo de un modo menos nebuloso al de las directoras argentinas cuando tratan de recrear las figuras de sus respectivos progenitores. Esta postura se puede apreciar 
si examinamos sus palabras en dicha entrevista cuando le preguntan qué imagen ha podido reconstruir de su padre y de su legado después de todos los años que ha dedicado a sus investigaciones. Ella responde que Carlos Pizarro era:

Un rebelde integral, que no se queda con la comodidad de su familia y su entorno social, pero que tampoco se queda en las Farc porque ahí no encontró el espacio que buscaba. Y cuando no se sintió cómodo en la guerra, también se le rebeló firmando la paz, un acto herético en ese entonces. Les llevó la contraria a los tiempos. Es un personaje que se me asemeja mucho a don Quijote, un hombre con una serie de valores en un tiempo en el que ya no existen: hablaba del honor, del respeto al enemigo, del valor de la palabra empeñada. Y tenía una relación con el arma que es muy distinta a la de un 'traqueto'. Era un hombre valiente, porque para ir en contravía de todo hay que ser valiente. (El Tiempo, 2016).

Si Carri no desea involucrarse en la política sino humanizar la figura de sus padres y entender la ausencia de éstos con Los rubios y todo el material que recoge para hacer la película, Roqué en Papá Iván presenta un padre en claroscuro, con grandes virtudes pero también con defectos notorios. No obstante, esta directora termina por aceptar que la realización de la película sobre su progenitor no le deja tantas respuestas como esperaba. Por ello considera que el filme no llega a constituirse en el epitafio simbólico que pensó que sería en la medida en que no le pudo dar punto final ni a sus cuestionamientos ni a su necesidad de honrar su memoria en ausencia de una tumba para hacerlo. Finalmente, María José Pizarro, que no es directora de cine como ellas, se presenta como artista plástica, superviviente y activista en la defensa de los derechos humanos y en la construcción de la paz, quehacer que muestra como el recibimiento de una bandera que le dejó su padre Carlos Pizarro Leongómez. ${ }^{21}$ Podemos concluir diciendo que, quizá como Sarlo propone, esta hija de excombatientes aspira a que la actividad posmemorística pueda convertirse también en una suerte de "memoria corregida" que ponga sobre el tapete los errores de los progenitores para examinarlos y enmendarlos aunque las heroicidades de estatua tengan que deslucirse un poco.

\section{Notas}

1. Véase Richard $(2007,143)$.

2. En el filme se menciona que, aunque Azucena Rodríguez hizo parte de la causa que se enfrentó a la dictadura argentina, se negó a dejar a sus hijos para pasar a la clandestinidad como lo hizo Juan Julio Roqué, en el año de 1972.

3. Myriam Rodríguez expresa en un testimonio que reproduce la página web de Casa Amèrica Catalunya: "Rápidamente, y a tiempo, había logrado escaparme en compañía de mis dos hijas, la mayor de 7 años y la pequeña de 8 meses de edad. Caminaba entre los piquetes de soldados que inundaban la ciudad, con una pequeña bolsa en donde llevaba los pañales y los biberones de mi hija y dos granadas de fragmentación" (2009).

4. Sobre esta temática, Fernán E. González González (2016) coincide con la visión de María José Pizarro y explica que el gobierno de Julio César Turbay Ayala fortalece la capacidad represiva del Estado a través del Estatuto de Seguridad. González dice de éste: "El Estatuto aumentaba las penas para los delitos de secuestro, extorsión y ataque armado y extendía la categoría de subversión para quienes adelantaran cualquier tipo de propaganda subversiva o incitara a la revuelta o a la desobediencia a las autoridades; además la fijación por estas penas era atribuida a autoridades subalternas militares, policiales y civiles" (González González 2016, 375-76).

5. En Los rubios, la amiga de la madre de Carri, al tiempo que recuerda el goulash que hacía Caruso y que califica como el mejor que llegó a probar, expresa: “... al mismo tiempo me la acuerdo revolviendo los ñoquis... con las dos niñitas dando vueltas por ahí, más vos que eras una bebita y mientras tanto haciéndome el bocho, porque su apariencia era la de Susanita, pero en realidad era Rasputín".

6. Roberto Carri y Ana María Caruso "fueron secuestrados por militares el 24 de febrero de 1977 y llevados al centro de detención llamado El Sheraton. Poco después los asesinaron dejando huérfanas a tres niñas: Andrea, de once años, Paula, de cinco y Albertina, de tres" (Rufinelli 2010, 160).

7. También empleó en la clandestinidad otros nombres como Lino y Martín como lo refieren sus compañeros.

8. Margoth Leongómez, madre de Carlos Pizarro, en el texto Las mujeres en la guerra de Patricia Lara dice a la periodista que su hijo "le pidió perdón al país muchas veces" (Lara 2001, 287) por la toma del Palacio de Justicia. Ella misma lo considera un inmenso error del comando del M-19 en aquella época.

9. De hecho, Carlos Pizarro en su correspondencia no sólo manifiesta su admiración por la obra de Gabriel García Márquez, a quien le dice, de modo familiar "El viejo Gabo" (Pizarro 2015, 85) sino que insiste en identificarse con el coronel Aureliano Buendía, quien perdió, en el universo creado por el escritor colombiano, todas las batallas en las que participó. La misma 
María José ha declarado que su dedicación al oficio de la joyería nace como una manera de rendirle un homenaje a su padre. En la entrevista realizada por Alfredo Molano Jimeno (2010), ella indica al respecto:

Mi papá decía que él era como el coronel Aureliano Buendía, que había peleado cien batallas y no había ganado ni una, y que al igual que el coronel, quería morir en un taller de alquimia haciendo pececitos de oro, porque eso requiere tal nivel de concentración que olvidaba los horrores de la guerra, y yo, que estudié joyería en Barcelona, me di cuenta de que es así, que es un mundo tan íntimo que tú empiezas a olvidar lo otro. Yo le hice su pescadito.

10. En este proyecto trabajaron el crítico peruano Julio Ortega y la esposa de Carlos Fuentes, la periodista Silvia Lemus. En la entrevista en El Tiempo, titulada "El libro llega en un momento perfecto", María José Pizarro dice que el proyecto tardó tanto que pensó que no iba a salir nunca. También expresa que el resultado final le agradó pues la considera reivindicadora de su padre: "El libro reivindica la imagen del guerrillero, y eso es muy importante si queremos alcanzar la paz porque es una forma de humanizar a los enemigos y de entender que no son sólo un grupo de asesinos, de entender los motivos por los que la gente entra en la insurgencia armada".

11. Un buen ejemplo de ello es la carta que Ana María Caruso dirige a su hija Paula, donde la felicita por su desempeño en el colegio al tiempo que le aconseja pedir ayuda a su círculo cercano o incluso a un analista para superar su nerviosismo. Caruso sugiere a su hija exponer, de manera franca, aquello que la perturba y reconoce su culpa por no estar con Albertina, ella y Andrea al expresar: "Yo sé que no es lo mismo que si estuviéramos nosotros y me siento muy culpable por no estar con ustedes" (Carri 2007, 95). Simultáneamente, le pide a Paula que cuide a Albertina, le sugiere que lea los libros que ha recomendado a Andrea y le pregunta por los preparativos para los sacramentos católicos que sabe que pronto hará. El padre, en cambio, se limita a agregar cuatro líneas escuetas en las que afirma: "Mamá ya les escribió todo lo que queríamos decirles" agregando unos cuantas palabras más y un breve saludo (Carri 2007, 95).

12. La razón por la cual deserta, según testimonio de su madre, fue porque "Carlos presenció en las Farc la ejecución de un compañero que había disentido" (Lara 2001, 275).

13. En el párrafo inicial de De su puño y letra, María José Pizarro explica que el 11 de septiembre de 1974 su padre había desertado de la guerrilla de las FARC y que, resguardándose de posibles represalias por su deserción, se ocultó en la casa de su amigo Nelson Osorio y de su esposa Marina (Pizarro 2015, 21). Aclara también que justo dos días después su madre llegó de Estados Unidos siendo éste el tiempo en que ellos se conocieron en una fiesta a la cual fueron invitados ambos.

14. María José Pizarro presenta apartados de cinco intervenciones diferentes dentro del mismo evento.

15. En el epistolario manifiesta su preocupación constante no sólo por el bienestar de María José sino que también se interesa por Claudia, a quien le dirige cartas y le dedica tiempo durante las visitas que ambas niñas le hacen en la prisión cuidando de que ésta no se sienta relegada por su hermana María José. De hecho dedica varias páginas cuestionando su habilidad para acercarse a Claudia dado el carácter tímido de ésta.

16. En la entrevista que la madre de Carlos Pizarro concede a Patricia Lara, la primera cuenta que, en determinado momento, tuvo que hacerse cargo de tres nietos: María José, Alejandra y Jacobo, los hijos respectivos de Carlos, Nina y Hernando pues éstos estaban encarcelados en Bogotá. En su testimonio, se refiere a los viajes que hacía de Cali a Bogotá para que sus nietos pudieran visitar a sus padres y a la dificultad de conseguir colegio para ellos puesto que en ninguna institución querían concederles cupo por ser hijos de guerrilleros.

17. Se ha transcrito la cita literal que asigna género femenino a la palabra torrente.

18. Carri expresa en la película tanto su incapacidad para entender la decisión tomada por sus padres como su ira por dicha decisión cuando afirma en la película: "Me cuesta trabajo entender la elección de mamá ¿por qué no se fue del país me pregunto una y otra vez. A veces me pregunto por qué me dejó aquí, en el mundo de los vivos. Y cuando llego a esta pregunta me revuelve la ira y recuerdo o eso creo, a Roberto Carri, mi padre y su ira o su labor incansable hasta la muerte". Se hace evidente la distinción de motivaciones que la hija adjudica al padre y a la madre puesto que sólo habla de la ira de su progenitor y no de la de su madre.

19. Horacio Bernades (2004) declara al respecto de la centralidad de la figura materna en Papá Iván: "Es Azucena, a todos los efectos, la que guarda la doble llave que María Inés busca. La llave que permite acceder a la formación, convicciones y militancia política de Iván y también, al mismo tiempo, a la novela familiar de los Roqué. De allí también que lo que da un eje narrativo a Papá Iván sea algo tan íntimo y personal como una carta manuscrita. La larga carta que Juan Julio dejó en 1972 para sus hijos. Y que, emocionalmente devastadora, funciona de manera tan distinta a la que la madre de un soldado muerto lee en Fahrenheit 9/11: lo que allí es un visible golpe de efecto, aquí representa, en cambio, una decisión personal asumida, la de llevar al plano de lo público la esfera de lo íntimo" 
20. En el guión que publica de su película, Albertina Carri explica que su hermana Paula le manifestó su deseo expreso de no hablar frente a las cámaras y que su hermana Andrea quiso colaborarle hablando frente a éstas, pero que solo decía cosas relevantes, desde su punto de vista, cuando ella apagaba la cámara.

21. En el momento presente María José Pizarro Rodríguez, como integrante del Movimiento Alternativo Indígena y Social -MAIS- encabeza la lista para las elecciones a la Cámara por Bogotá, que se realizarán el 11 marzo de 2018. Su partido ha hecho una coalición denominada "lista de la decencia" con los partidos Colombia Humana, Todos Somos Colombia, UP y ASI, según lo referencia el portal digital Las2orillas.

\section{Obras citadas}

Amado, Ana. 2009. La imagen justa: cine argentino y política (1980-2007). Buenos Aires: Colihue.

Bernades, Horacio. "La carta abierta de una hija a su padre montonero.” En Página 12, 29 julio 2004. https://www.pagina12.com. ar/diario/espectaculos/6-38899-2004-07-29.html

Carri, Albertina. 2007. Los rubios: cartografía de una película. Buenos Aires: Gráficas Especiales.

Casa Amèrica Catalunya. "Myriam Rodríguez, ex-guerrillera del M-19 de Colombia: 'Queríamos romper el silencio, poner rostros a la revolución y hacer propuestas al país'." En Casa Amèrica Catalunya, 15 mayo 2009. http://americat.barcelona/ es/myriam-rodriguez-ex-guerrillera-del-m-19-de-colombia-queriamos-romper-el-silencio-poner-rostros-a-la-revolucion-yhacer-propuestas-al-pais-i

Fuentes, Carlos. 2016. Aquiles o el guerrillero. Bogotá: Alfaguara.

Guevara, Ernesto. 1977. El socialismo y el hombre nuevo. México: Siglo XXI.

González González, Fernán E. 2016. Poder y violencia en Colombia. Bogotá: Odecofi-Cinep.

Hirsch, Marianne. 1997. Family Frames: Photography, Narrative, and Postmemory. Cambridge: Harvard University Press.

Quílez, Laia. 2007. "Autobiografía y ficción en el cine documental argentino. Los rubios de Albertina Carri: un caso paradigmático.” En El cine argentino de hoy: entre el arte y la política, ed. Viviana Rangil, 72-85. Buenos Aires: Biblos.

Lara, Patricia. 2001. Las mujeres en la guerra. Bogotá: Planeta.

Molano Jimeno, Alfredo. "María José Pizarro: en el nombre del padre." En El Espectador, 14 noviembre 2010. https://www.elespectador.com/entretenimiento/arteygente/gente/articulo-234914-maria-jose-pizarro-el-nombre-del-padre

Pizarro, Carlos. 2015. De su puño y letra. Bogotá: Debate.

Papá Iván. 2004. Dir. María Inés Roqué. CCC-Zafra. Filme

Pizarro. 2016. Dir. Simón Hernández. Producciones La Popular. Filme

R, Yaninne. "María José Pizarro encabeza la lista de la decencia a la Cámara de Bogotá." En Las2orillas, 11 diciembre 2017. https://www.las2orillas.co/maria-jose-pizarro-encabeza-la-lista-de-la-decencia-la-camara-de-bogota/

Richard, Nelly. 2007. Fracturas de la memoria. Arte y pensamiento crítico. Buenos Aires: Siglo XXI.

Ruffinelli, Jorge. 2010. América Latina en 130 documentales. Santiago de Chile: Uqbar.

Los rubios. 2003. Dir. Albertina Carri. Primer Plano. Filme. 
Sarlo, Beatriz. 2006. Tiempo pasado. Cultura de la memoria y giro subjetivo. Una discusión. México: Siglo XXI.

El Tiempo. "El libro llega en un momento perfecto." En El Tiempo, 21 mayo 2016. http://www.eltiempo.com/archivo/documento/ $\underline{\text { CMS-16599148 }}$ 